NBER WORKING PAPER SERIES

CROWDING OUT OR CROWDING IN?

EVIDENCE ON DEBT-EQUITY SUBSTITUTABILITY

Benjamin M. Friedman

Working Paper No. 1565

NATIONAL BUREAU OF ECONOMIC RESEARCH

1050 Massachusetts Avenue

Cambridge, MA 02138

February 1985

The research reported here is part of the NBER's research program In Financial Markets and Monetary Economics and projects in Debt Equity and Government Budget. Any opinions expressed are those of the author and not those of the National Bureau of Economic

Research. 
NBER Working Paper \#1565

February 1985

\author{
Crowding Out or Crowding In? \\ Evidence on Debt-Equity Substitutability
}

\title{
ABSTRACT
}

When the composition of assets outstanding in the market changes, the pattern of expected asset returns also changes, shifting to whatever return structure will induce investors to hold just the new composition of exisiting assets. The object of this paper is to determine, on the basis of the respective risks associated with the returns to broad classes of financial assets in the United States, and hence on the basis of the implied portfolio substitutabilities among these assets, how government deficit financing affects the structure of market-clearing expected returns on debt and equity securities traded in U.S. markets.

The empirical results indicate that government deficit financing raises expected debt returns relative to expected equity returns, regardless of the maturity of the government's financing. More specifically, financing a single $\$ 100$ billion government deficit by issuing short-term debt lowers the expected return on long-term debt by .06\%, and lowers the expected return on equity by $.33 \%$, relative to the return on short-term debt. Financing a $\$ 100$ billion deficit by issuing long-term debt raises the expected return on long-term debt by . $10 \%$, but lowers the expected return on equity by . $24 \%$, again in comparison to the return on short-term debt. These per-unit magnitudes are not huge, but in the current U.S. context of government deficits approximating $\$ 200$ billion - year after year - they are not trivially small either.

These results have immediate implications for the composition of private financing. In addition, in conjunction with some assumption (for example, about monetary policy) to anchor the overall return structure, they bear implications for the total volume of private financing, as well as for capital formation and other interest-sensitive elements of aggregate demand.

Benjamin M. Friedman

Harvard University

Department of Economics

Littauer Center 127

Cambridge, MA 02138

(617) $495-4246$ 
To what extent - indeed, whether - government deficit financing "crowds out" private financing and private capital formation depends, in the first instance, on how deficit financing affects the structure of the market returns on debt and equity securities. How market returns respond to such influences as issues of government debt depends, in turn, on the relative asset substitutabilities that characterize security holders' portfolio behavior. Unless investors regard debt and equity as perfect substitutes, even the sign of the effect of government debt issues on the market-clearing expected return on equity depends on the relative degrees to which investors treat debt, equity and other classes of assets as portfolio substitutes. In a world in which firms finance investment by equity lor some combination of debt and equity), therefore, whether government deficit financing "crowds out" or "crowds in" private capital formation depends also on relative asset substitutabilities. ${ }^{1}$

When the composition of the assets outstanding in the market changes, the pattern of expected asset returns must in general change also, shifting to whatever return structure will induce investors to hold just the new composition of existing assets. Under most familiar circumstances, increasing the market supply of any specific asset raises that asset's market-clearing expected return. ${ }^{2}$ By contrast, an increase in the supply of any one asset may either raise or lower the expected return on any other asset. The expected returns on assets that investors regard as close substitutes - for example, government debt and high-grade corporate debt of comparable maturity - 
presumably move closely together. If investors do not regard two assets as close substitutes, an increase in the market supply of one may well lower the expected return on the other. The question here, in short, is whether investors regard debt and equity securities as close or distant substitutes. According to the standard theory describing the portfolio behavior of risk-averse investors, the relevant asset substitutabilities that determine whether "crowding out" or "crowding in" occurs depend on investors" perceptions of the risks associated with holding debt, equity and other assets. Investors' willingness to hold different assets depends on their assessments of the respective risks to which holding these assets exposes them, and their treatment of some assets as substitutes for others in their portfolios likewise depends on the relationships they perceive among the associated risks to holding these assets as well as others. If two assets expose holders to essentially the same set of risks, investors typically treat the two as close substitutes and allocate their portfolios accordingly. Assets subject to quite disparate risks are typically more distant substitutes, or perhaps even complements.

The object of this paper is to determine, on the basis of the respective risks associated with the returns to broad classes of financial assets in the United states, and hence on the basis of the implied portfolio substitutabilities among these assets, how government deficit financing affects the structure of market-clearing expected returns on debt and equity securities traded in U.S. markets. The chief line of analysis followed here is to infer investors' unobservable perceptions of asset risks by applying a multivariate regression procedure with continual re-estimation over time, based on actual return data, and then to apply the standard theory of risk-averse portfolio allocation to infer the relevant parameters of investors' asset demands . 
Any such analysis of relative asset substitutabilities cannot, of course, answer by itself the question of the extent to which returns on all assets together move in response to government deficit financing. Inferences about joint movements of all asset returns would require in addition some further assumption - for example, about monetary policy - to anchor the overall return structure. To anticipate, the conclusion that follows from this analysis is that financing government deficits by issuing short-term debt lowers the return on long-term debt and lowers the return on equity by even more, while financing deficits by issuing long-term debt raises the return on long-term debt but lowers the return on equity, all in comparison to the benchmark of the return on short-term debt.

Section I briefly sets out the underlying portfolio-theoretic relationships on which the analysis relies. Section II outlines the multivariate regression procedure for inferring investors' risk perceptions over time, and documents the main properties of the associated expectations and expectation errors. Section III examines the implications that follow for investors' portfolio behavior in general, and for the "crowding out" question in particular, from this representation of investors' perceptions. Section IV tests the robustness of these results to the particular data used to construct the asset return series by repeating parts of the analysis using data exhibiting quite different serial correlation properties. Section $\mathrm{V}$ reports the results (largely unsuccessful) of an altemative approach applying maximum likelihoood methods to estimate investors' behavior using data on the aggregate portfolio of U.S. households. Section VI summarizes the principal conclusions of this analysis, and calls attention to several important caveats. 


\section{Asset Risks and Asset Returns}

Following the standard discrete-time theory of risk-averse portfolio choice, the investor's single-period objective as of time $t$, given initial wealth $w_{t}$, is

$$
\max _{\frac{\alpha}{t}} E\left[U\left(\tilde{W}_{t+1}\right)\right]
$$

subject to

$$
\underline{\alpha}{ }_{t}^{\prime} \underline{1}=1
$$

where $E(\cdot)$ is the expectation operator, $U(W)$ is utility as a function of wealth, $\underline{\alpha}$ is a vector expressing portfolio allocations in proportional form

$$
\frac{\alpha}{t}=\frac{1}{W_{t}} \cdot \frac{A}{t}
$$

for vector $\underline{A}$ of asset holdings, and wealth evolves according to

$$
\tilde{w}_{t+1}=w_{t} \cdot \frac{\alpha^{\prime}}{t}\left(1+\tilde{x}_{t}\right)
$$

for real net asset returns $\underline{r}$.

Under the conditions that $U(W)$ is any power or logarithmic function (so that the Pratt-Arrow coefficient of relative risk aversion is constant), 3 that the investor perceives asset returns $\underline{r}$ to be distributed normally (or lognormally) with expectation $\underline{r}^{e}$ and variance-covariance structure $\Omega, 4$ and that no asset in vector $\underline{A}$ is riskless in real terms, ${ }^{5}$ solution of (1) subject to (2) yields

$$
\left.\underline{\alpha}_{t}^{*}=B_{t} \frac{\left(x^{e}\right.}{t}+\underline{1}\right)+\pi_{t}
$$


where

$$
\begin{aligned}
& B_{t}=\left\{\frac{-U^{\prime}\left[E\left(\tilde{W}_{t+1}\right)\right]}{W_{t} \cdot U^{\prime \prime}\left[E\left(\tilde{W}_{t+1}\right)\right]}\right\} \cdot\left[\Omega_{t}^{-1}-\left(\underline{1} \cdot \Omega_{t}^{-1} 1\right)^{-1} \Omega_{t}^{-1} \underline{1} \underline{1}^{\prime} \Omega_{t}^{-1}\right] \\
& \underline{\pi}_{t}=\left(\underline{I}^{\prime} \Omega_{t}^{-1}\right)^{-1} \Omega_{t}^{-1} \underline{1} .
\end{aligned}
$$

If the time unit is sufficiently small to render $w_{t}$ a good approximation to $E\left(\tilde{w}_{t+1}\right)$ for purposes of the underlying expansion, then the first (scalar) term within brackets in (6) is simply the reciprocal of the constant coefficient of relative risk aversion. ${ }^{6}$

Matrix B in (5), expressing the response of each proportional asset demand to movements in the expected real returns on that and other assets, contains the set of relative asset substitutabilities that determine how increases in asset supplies affect the market-clearing structure of expected returns. The solution for $B$ in (6) makes clear the central role of investors' risk perceptions in governing this behavior. The asset substitutabilities in $\mathrm{B}$ depend only on the investor's risk aversion and risk perceptions, here parameterized by a variance-covariance matrix $\Omega$ that in general may vary over time.

The determination of expected returns follows from equating the aggregate of all investors' asset demands to the net market supplies of all assets. Because of the linearity in expected returns, which follows here from the assumption of constant relative risk aversion and joint normally distributed assessments of asset returns, the asset demand relationships in (5) readily admit of aggregation across investors with diverse preferences and endowments. ${ }^{7}$ The relevant market-clearing condition is then just

$$
\frac{A}{t}=\frac{\AA}{t}
$$


where $\underline{A}$ is now the aggregate vector of all investors' individual asset demands as in (2), and $\underline{A}^{S}$ is the aggregate vector of assets supplied by initial conditions on "outside" issuers. 8

Solution of (8) determines the relative expected returns on all assets, or, equivalently, the absolute expected returns on all assets but one. The market-clearing response of any asset's expected return to a change in the supply of any "outside" asset follows from (5) and (8) as

$$
\frac{\partial r_{i}^{e}}{d A_{j}^{S}}=\frac{1}{W} \cdot\left(\beta_{i j}^{-1}-\underline{\beta}_{i}^{-1} \underline{\alpha}\right)
$$

where $\beta_{i j}^{-1}$ and $\underline{B}_{i}^{-1}$ are, respectively, the $i j-t h$ element and the $i-$ th row of the inverse of matrix B after deletion of any row and any column (other than the $i-t h$ or $j-t h)$. Once again, given the direct dependence of $B$ on $\Omega$ via (6), the central importance of investors' risk perceptions in governing how market-clearing expected returns respond to changes in asset supplies is readily apparent. 


\section{A Representation of Investors' Risk Perceptions}

Table 1 indicates the 1960-1980 means, together with the associated unconditional quarterly variances and covariances, of the after-tax real per annum returns on three broad classes of U.S. financial assets that differ fundamentally from one another according to the risks associated with holding them: Short-term debt includes all assets bearing real returns that are risky, over a single year or calendar quarter, only because of uncertainty about inflation. By contrast, long-term debt is risky because of uncertainty not only about inflation but also about changes in asset prices directly reflecting changes in market interest rates. Similarly, equity is risky because of uncertainty about inflation and about changes in stock prices.

The pre-tax nominal return associated with the short-term debt category here is a weighted average of zero (for money), the Federal Reserve average rate on time and saving deposits (for other deposits bearing regulated yields), and the four-to-six month prime commercial paper rate (for all other instruments maturing in one year or less), weighted in each quarter according to the composition of the U.S. household sector's aggregate portfolio. The pre-tax nominal return on long-term debt is the Moody's Baa corporate bond yield, plus annualized percentage capital gains or losses approximated by applying the standard consol formula to changes in the Baa yield. For equity the pre-tax nominal return is the dividendprice yield, plus annualized percentage capital gains or losses, on the Standard and Poor's 500 index. For each asset the corresponding aftertax real return is calculated by applying the household sector's average effective marginal tax rates in each year for interest, dividends and capital gains to the respective components of the pre-tax nominal returns, 
MEANS AND VARIANCE-COVARIANCE STRUCTURE OF AFTER-TAX REAL RETURNS, 1960-1980

Means
Short-Term Debt $\left(r_{S}\right)$
$-2.80 \%$
Long-Term Debt $\left(r_{L}\right)$
$-3.83$
Equity $\left(r_{E}\right)$
3.13

Variance-Covariance Matrix

$\begin{array}{lll}{ }^{r_{S}} & \frac{r_{L}}{r_{E}} \\ 11.18 & & \\ 29.91 & 209.35 & \\ 30.24 & 161.77 & 597.96\end{array}$


and then subtracting the annualized percentage change in the consumer price index. 9

The after-tax real returns on all three classes of assets were serially correlated during this period, with simple first-order serial correlation coefficients of .86 for short-term debt, .51 for long-term debt, and .33 for equity, based on quarterly observations for 1960-1980. The unconditional variance-covariance matrix shown in Table 1 therefore presumably overstates the uncertainty that investors actually associated with their expectations of asset returns, over each coming calendar quarter, throughout this period. The object of the analysis here is to construct a representation of investors' perceptions of these risks that takes more careful account of what information investors did or did not have at any particular time.

As of the beginning of each calendar quarter, investors presumably know the stated interest rates on short-term debt instruments, the current prices and the coupon rates on long-term debt instruments, the current prices and (approximately) the dividends on equities, and the relevant tax rates. The three uncertain elements that they must forecast over the coming quarter, in order to form expectations of the after-tax real returns on the three broad classes of assets considered here, are inflation $\left(\dot{P}_{I}\right)$, the capital gain or loss on long-term debt $\left(\dot{\mathrm{P}}_{L}\right)$, and the capital gain or loss on equity $\left(\dot{\mathrm{P}}_{E}\right)$.

The procedure used here to infer investors' risk perceptions represents investors as forming expectations of these three uncertain return elements, at each point in time, by estimating a multivariate linear regression model giving the best linear projection of these elements from past values 


$$
\frac{\dot{p}}{t}=\Gamma(L \mid t-1) \dot{p}_{t-1}
$$

where $\underline{\dot{P}}$ is the vector with elements $\left(\dot{\mathrm{P}}_{I^{\prime}}, \dot{\mathrm{P}}_{L^{\prime}} \dot{\mathrm{P}}_{E}\right)$ and $\Gamma(L \mid t-1)$ is a matrix of polynomials in the lag operator, estimated by applying ordinary least squares to the vector autoregression (with disturbance vector $\underline{u}$ )

$$
\underline{\dot{p}}_{\tau}=\Gamma(L) \underline{\dot{p}}_{\tau-1}+\underline{u}_{\tau}
$$

using observations on $\underline{\dot{p}}$ for sample period $\tau=1, \ldots, t-1$. In other words, at the beginning of each period investors estimate (11) using all then-available data (through the immediately preceding period), and then use the estimated model to project inflation and the respective capital gains on long-term debt and equity for the period immediately ahead as in (10). After that period elapses, investors incorporate the new observation on the three random variables into the sample, re-estimate (11), and use the up-dated model to project the relevant unknowns for the subsequent period. For each time period $t,(10)$ gives an expectation $\frac{\dot{p}_{t}^{e}}{t}$. Each such expectation has associated with it an estimated variance-covariance structure

$$
\left.\Phi_{t}=E\left[\dot{\dot{p}}_{t}-\underline{\dot{p}}_{t}^{e}\right)\left(\dot{\dot{p}}_{t}-\frac{\dot{p}}{t}\right) \cdot\right]
$$

Because each of the three real returns in $\underline{r}$ is just a linear combination of the elements of $\underline{\dot{p}}$ plus a component assumed to be known with certainty as of the beginning of the period, the relevant set of real return expectations for each period $t$ follows as

$$
\underline{\underline{r}}_{t}^{e}=\Lambda \dot{p}_{t}^{e}+\frac{\lambda}{t}
$$

and the associated variance-covariance matrix follows as 


$$
\Omega_{t}=\Lambda \Phi \Lambda^{\prime}
$$

where, for tax rate $k$ on capital gains, ${ }^{10}$

$$
\Lambda=\left|\begin{array}{ccc}
-1 & 0 & 0 \\
-1 & (1-k) & 0 \\
-1 & 0 & (1-k)
\end{array}\right|
$$

and $\frac{\lambda}{t}$ is the vector with elements comprised entirely of components of $\underline{r}_{t}$ assumed to be known with certainty as of the beginning of period $t$.

The three panels of Figure 1 exhibit the forecasting performance of this continually updated regression procedure for each quarter during 1960-1980. The respective panels' heavy solid lines show the actual movements of inflation, the capital gain on long-term debt, and the capital gain on equity, while the broken lines show the corresponding series of one-period-ahead forecasts. (Because of the greater volatility of capital gains on long-term debt and especially equity, the three panels are drawn to different scales.) For $1960:$ I the three forecasts are based on (10), with lag lengths $L=1, \ldots, 4$, estimated using data for $1953: I I-1959: I V .^{11}$ For $1960:$ II the procedure is the same except that the data used to estimate (10) spans $1953:$ II-1960:I. The procedure is analogous for each subsequent period, ending with the use of data for 1953:II-1980:III to estimate (10) to generate the one-period-ahead forecasts for $1980:$ IV. 12

As is clear from the figure, this inherently backward-looking forecast procedure enjoys the advantages and suffers the shortcomings of expecting the immediate future to be like the immediate past, so that the degree of success achieved by the resulting one-period-ahead forecasts naturally varies according to the extent of the serial correlation in the series being 

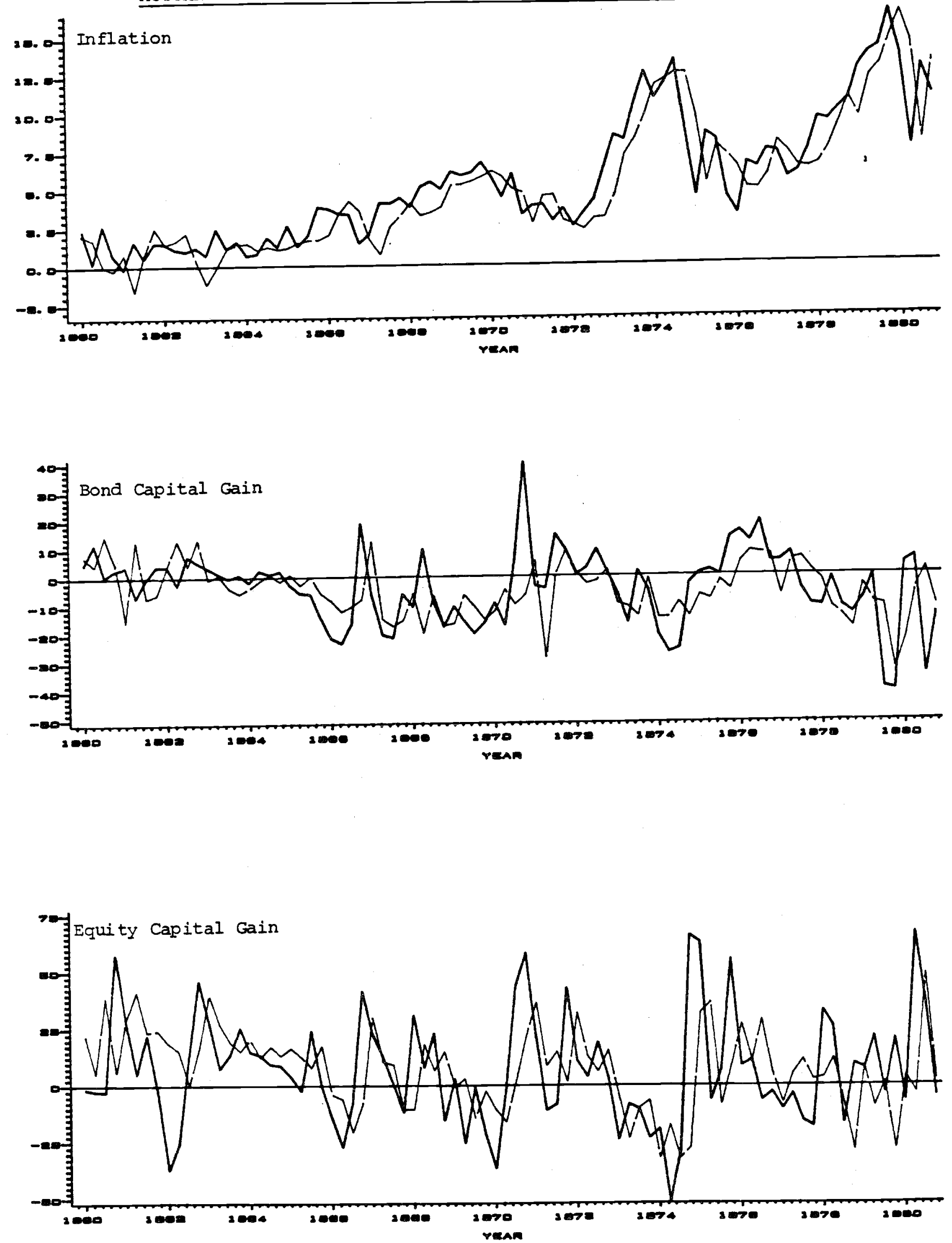
forecast. The first-order serial correlation coefficients of the realizations of the three random variables are .90 for price inflation, .44 for long-term debt capital gains, and .31 for equity capital gains, again based on quarterly movements during 1960-1980. The simple correlation coefficients between the realizations and the corresponding forecasts derived from continual updating of (10) are .88 for inflation, .42 for long-term debt capital gains, and .23 for equity capital gains. I3

The three panels of Figure 2 exhibit the forecasting performance for the after-tax real returns implied by these one-period-ahead forecasts of the uncertain asset return elements as in (13). The heavy solid lines show actual movements of the three asset returns, while the broken lines show the corresponding series of one-period-ahead forecasts. (The three panels here are again drawn to different scales). For the uncertain asset returns, as for the underlying uncertain components, the forecasting procedure represents the future as resembling the immediate past, so that the success achieved by the respective forecasts varies according to the serial correlation in the different asset returns. The simple correlation coefficients between the realizations of after-tax real returns and the corresponding forecasts are .83 for short-term debt, .51 for long-term debt, and .30 for equities.

Table 2 shows the 1960-1980 means of these one-period-ahead forecasts. Comparison with the corresponding actual means shown in Table 1 indicates that, on average, the forecasts generated by this procedure were somewhat too optimistic about the returns on short-term debt and on equities. The forecasts of the return on long-term debt were somewhat too pessimistic on on average. In each case, however, the mean absolute error is less than $1 \%$ 
FIGURE 2

ACTUAL RETURNS AND REGRESSION-BASED FORECASTS, 1960-1980
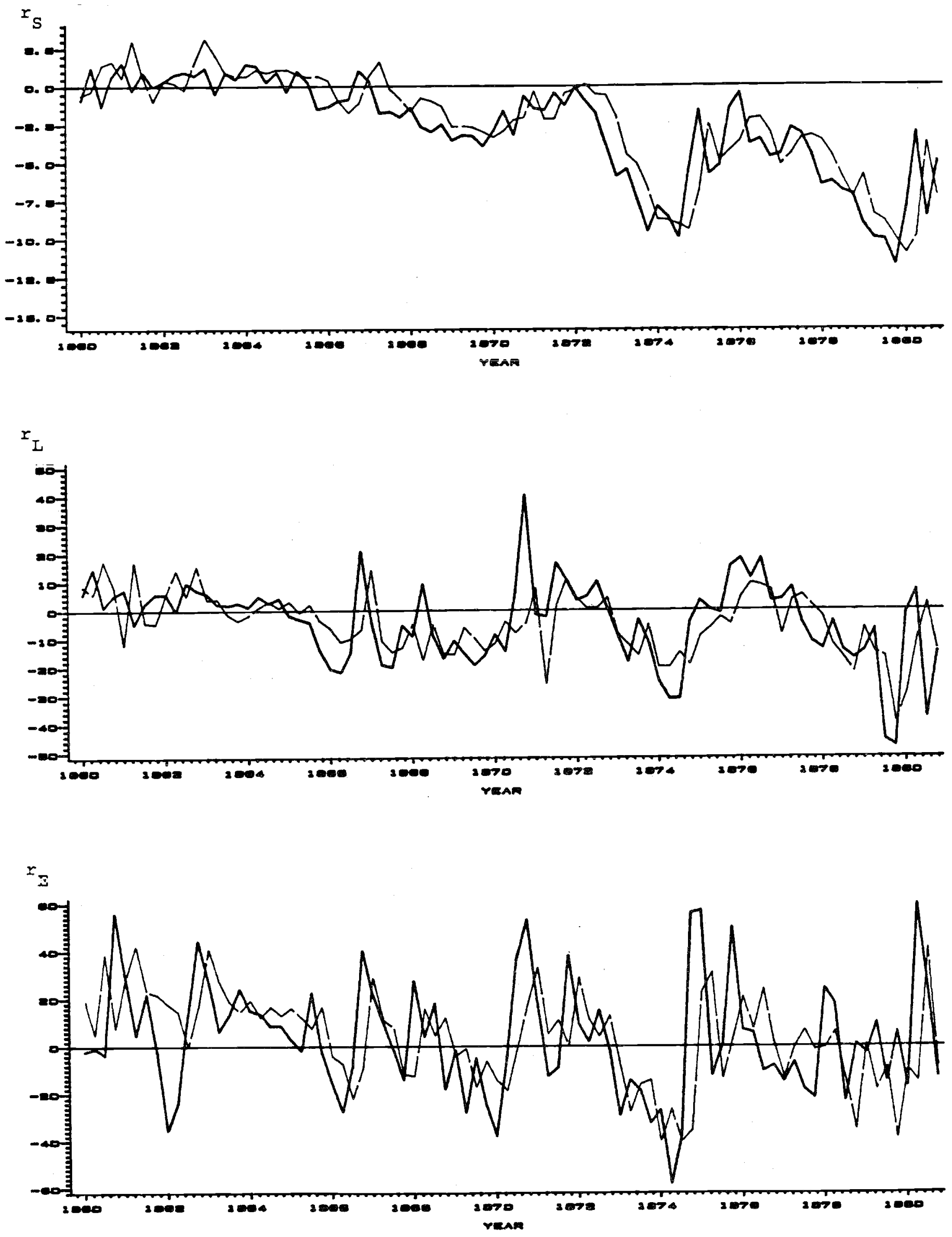
TABLE 2

MEANS AND MEAN VARIANCE-COVARIANCE STRUCTURE OF FORECAST RETURNS, 1960-1980

Means

$\begin{array}{lc}\text { Short-Term Debt }\left(r_{S}\right) & -2.40 \% \\ \text { Long-Term Debt }\left(r_{L}\right) & -4.40 \\ \text { Equity }\left(r_{E}\right) & 3.73\end{array}$

Mean of Associated Variance-Covariance Matrices

$\underline{r_{S}} \quad \underline{r_{L}} \quad \underline{r_{E}}$

$r_{\mathrm{S}}$

$r_{\text {L }}$

3.62

76.61

$r_{\mathrm{E}}$

6.45

48.09

317.27 
per annum.

Table 2 also shows the 1960-1980 means of the variances and covariances associated with these forecasts, constructed not from the ex post forecast errors (which investors would not have known in entirety until after 1980 :IV) but by averaging, over the eighty-four individual quarters in this period, the ex ante conditional variances and covariances associated with each period's forecast via (14). These conditional variance and covariance averages are uniformly smaller than the corresponding unconditional variances and covariances shown in Table 1 . The large margin of difference in each case reflects the importance of investors' having (and using) information about recent realizations when the returns they are trying to forecast are serially correlated. 


\section{Implications for Portfolio Behavior}

Together with a value for the market-average risk aversion, the variance-covariance matrix summarizing investors' risk perceptions directly implies the key asset substitutabilities that characterize investors' portfolio behavior. Because the procedure described in Section II allows for the fact that the information investors have changes from one period to the next, it generates a different such variancecovariance matrix for each period. It therefore implies a different matrix of asset substitutabilities for each period.

Figure 3 shows the variation over time of the six elements of matrix B calculated by applying the transformation given in (6), up to but not including multiplication by the reciprocal of the coefficient of relative risk aversion, to the eighty-four individual quarter conditional variancecovariance matrices derived via the procedure described in section II. ${ }^{14}$ The variation of these $\beta_{i j}$ elements over time reflects a combination of investors' growing amount of information (starting from the 1953:II base) and their reaction to specific "surprise" episodes that are also readily visible in the actual return series plotted in Figure 2. More information implies smaller variances and covariances, and hence larger (in absolute value) responses, while the immediate effect of "surprises" is just the opposite. Prominent examples of such "surprises" that are visible in Figure 2, and that have noticeable effects on the $\beta_{i j}$ values plotted in Figure 3, include the stock market crash in 1962, the "credit crunch" in 1966, the Penn Central default in 1970, the combination of OPEC and tight monetary policy in 1974, and the Federal Reserve System's introduction of new monetary policy procedures in 1979.

Two more general features of these $\beta_{i j}$ values that persist over 

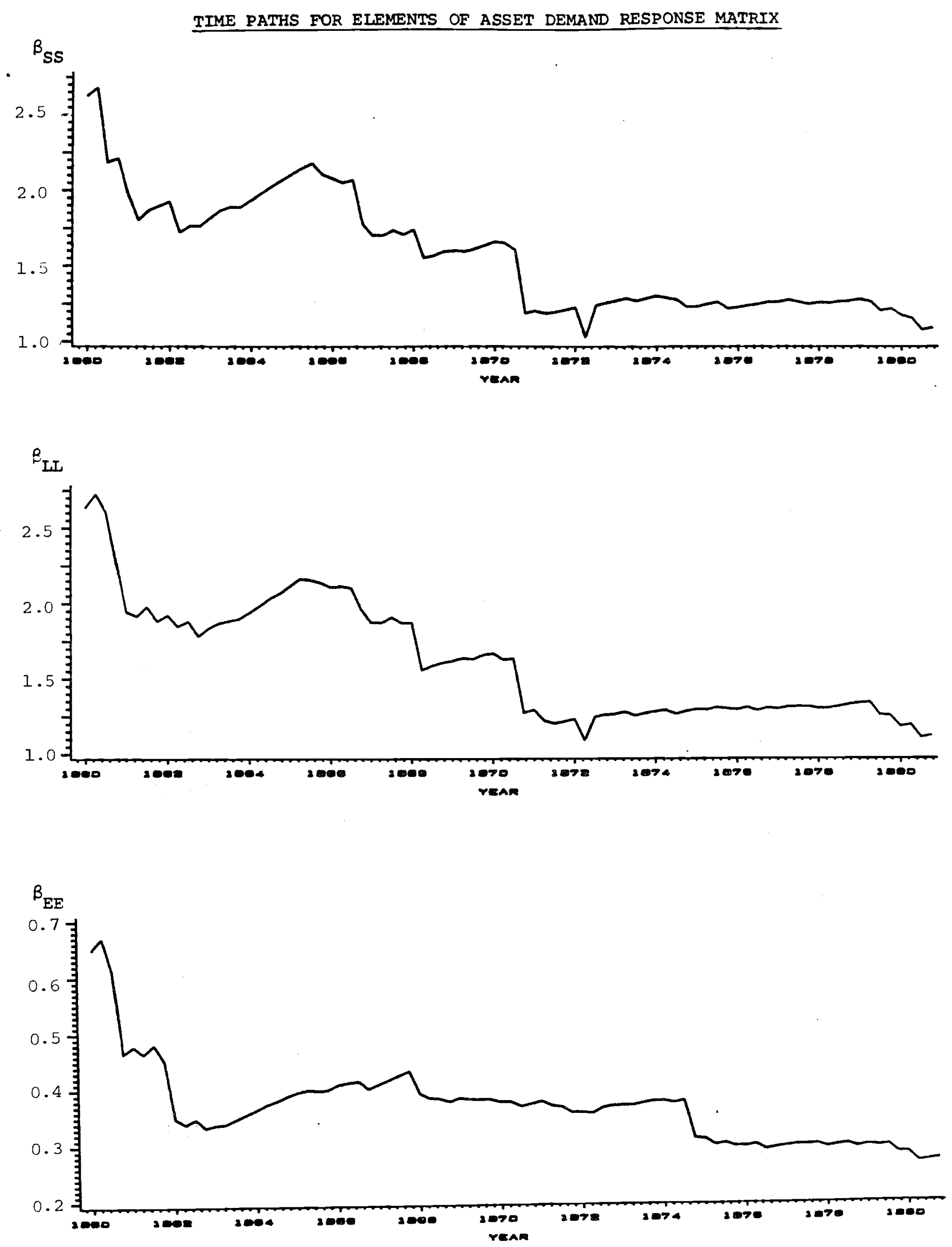

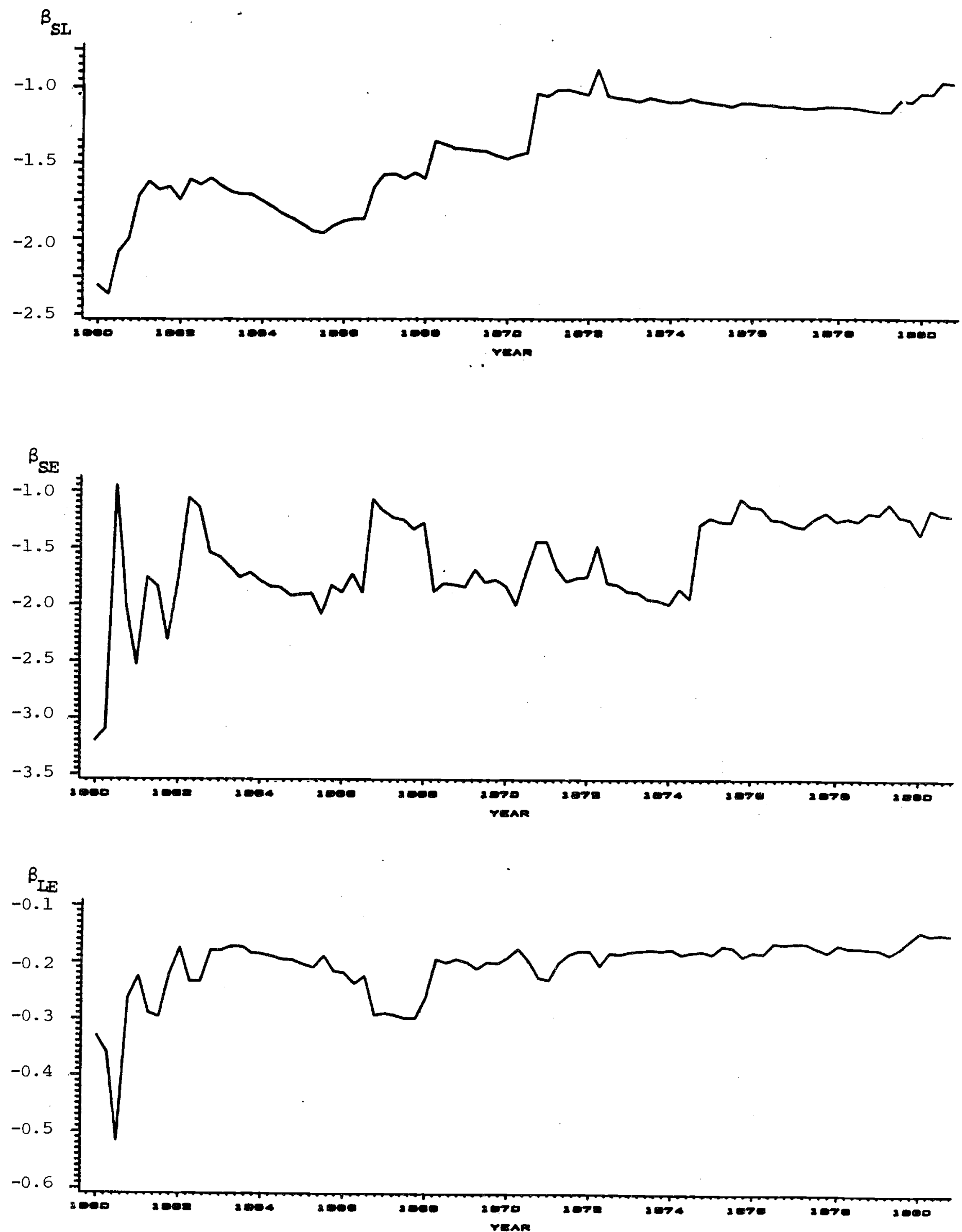
on investors' risk perceptions. For the short-term debt return assumed to be fixed, the results shown in Table 3 indicate that the expected longterm debt return and the expected equity return fall by $.06 \%$ and $.33 \%$, respectively, in response to each $\$ 100$ billion additional supply of shortterm government debt to be held in investors' aggregate portfolio. The expected differential between the returns on equity and long-term debt (which is presumably positive, from past experience) narrows by $.27 \%$. For a $\$ 200$ billion deficit, as has been more nearly the case in recent years, the effects are exactly double the magnitudes shown.

similarly, if the government finances its deficit by issuing longterm debt, the expected return on long-term debt presumably rises in comparison to the expected returns on other assets. If the short-term debt return is fixed, the long-term debt return therefore rises absolutely, and the returns on other assets may either rise or fall. Which other assets' returns rise and which fall again depends on relative asset substitutabilities, and hence on investors' risk perceptions. The results shown in Table 3 indicate that the expected long-term debt return rises by $.10 \%$ and the expected equity return falls by .248 in response to each $\$ 100$ billion additional supply of long-term government debt. The expected differential between the returns on equity and long-term debt again narrows, this time by $.34 \%$. Once again, for a $\$ 200$ billion deficit the effects are just twice as large.

These results imply that the effects of financing government budget deficits lead to market incentives to emphasize reliance on equity (including earnings retentions for corporations) and reduce reliance on debt, in comparison with the composition of business and individual financing that would prevail in the absence of the need to finance the government 
deficit. Because these results describe effects only on relative returns, rather than effects on absolute levels of returns, by themselves they answer questions about the composition of financing but not about its total. Nevertheless, in conjunction with some further assumption to anchor the overall return structure - for example, that monetary policy accommodates the deficit so as to keep expected short-term real returns unchanged, or, alternatively, that monetary policy is not accommodative and hence lets expected short-term real returns rise if the deficit is large enough - these results also bear straightforward implications for the total volume of financing and, in turn, for capital formation and other typically interest-sensitive elements of aggregate demand. 
IV. Results Based on Alternative Return Data

One of the striking features of the observed asset return series noted in section II is the high degree of positive serial correlation, even in the long-term debt and equity capital gain terms, that is readily visible in Figure 1. Under the standard theory of speculative asset markets, it is plausible to suppose that these serial correlations are in part the result of the use of time-averaged data. ${ }^{21}$ Because the heart of the vector autoregression procedure outlined in section II consists of exploiting the serial correlation properties of the series to be projected, it is important to be sure that the results reported in section III are not simpiy an artifact due to time averaging.

The upper panel of Table 4 shows the unconditional quarterly variances and covariances of the after-tax real per annum returns on the same three assets considered in sections II and III, calculated from 1969-80 data designed to eliminate time averaging in so far as is possible. For short-term debt, the nominal return is a weighted average of zero, the average time and saving deposit rate for the entire quarter, and the commercial paper rate for the last month of the quarter. ${ }^{22}$ For long-term debt, the nominal return is the Moody's Aaa rate as of the last day of the quarter plus the annualized change in Ibbotson and Sinquefield's (1982) bond price index from the last day of one quarter to the last day of the next. For equity, the nominal return is the standard and Poor's 500 dividend for the quarter plus the annualized change in Ibbotson and Sinquefield's equity price index (actually the same index) from the last day of one quarter to the last day of the next. For each asset the difference between the nominal and real (pre-tax) return is the annualized change in the consumer price index measured as of the last month of the quarter. The calculation of after-tax returns from the 


\section{TABLE 4}

VARIANCE-COVARIANCE STRUCTURES BASED ON POINT-IN-TIME DATA 1969-1980

Unconditional Variance-Covariance Matrix

$\begin{array}{lccc} & \stackrel{r_{S}}{r_{L}} & \underline{r_{E}} \\ r_{S} & 10.75 & & \\ r_{L} & 28.35 & 632.97 & \\ r_{E} & 43.86 & 387.22 & 1275.29\end{array}$

Mean of Conditional Variance-Covariance Matrices

$\begin{array}{llll} & \underline{r_{S}} & \underline{r_{L}} & \underline{r_{E}} \\ r_{S} & 1.41 & & \\ r_{L} & 6.04 & 120.94 & \\ r_{E} & 10.05 & 73.78 & 478.39\end{array}$


respective pre-tax returns is as in section II.

Except for the inflation rate, these data exhibit serial correlation properties quite different from those described in section II and plotted in Figures 1 and 2. The first-order serial correlation coefficients for the three after-tax real returns during this period were .70 for short-term debt, -.32 for long-term debt, and .18 for equity. For the three individual elements taken to be uncertain in the forecasting procedure outlined in section II, the corresponaing firist-order serial correlation coefficients are .81 for price inflation, -.32 for long-term debt capital gains, and .16 for equity capital gains.

The lower panel of Table 4 shows the mean values of the individual quarter variance-covariance matrix elements that result from applying the procedure of $(10)-(15)$ to these alternative data. Although the individual elements differ from those shown in Table 2, here as in Section II the variances and covariances associated with the continually updated forecasts are uniformly smaller than the corresponding unconditional variances and covariances. Except for inflation and the short-term debt return, however, here the smaller serial correlations lead - as would be expected with an autoregressive procedure - to less successful forecasts. The simple correlation coefficients between the realizations and the corresponding forecasts from continual updating of (10) for these data are .90 for inflation, .16 for the long-term debt capital gain, -.17 for the equity capital gain, and $.87, .34$ and .25 for the after-tax real returns on short-term debt, long-term debt and equity, respectively. Table 5 summarizes the implications of these differences for investors" portfolio behavior and the consequent effects of government deficit financing. As in Table 3, the upper panel of the table shows the means of the six 
Asset Demand Response Matrix

$\begin{array}{lccc} & r_{S} & r_{L} & \underline{r_{E}} \\ \alpha_{S} & 2.06 & & \\ \alpha_{L} & -1.84 & 1.94 & .306 \\ \alpha_{E} & =.214 & -.0920 & \end{array}$

Effects of Government Deficit Financing (per \$loo billion)

$\begin{array}{lcc} & -\Delta S & \Delta I_{1} \\ \text { Effect on }\left(r_{L}-r_{S}\right) & -.038 & .098 \\ \text { Effect on }\left(r_{E}-r_{S}\right) & -.31 & -.27 \\ \text { Effect on }\left(r_{E}-r_{I}\right) & -.28 & -.37\end{array}$


elements of $\mathrm{B}$ calculated for each quarter by applying the transformation given in (6) to that quarter's implied variance-covariance matrix from (14), up to but not including multiplication by the risk aversion coefficient reciprocal. The lower panel shows the effects of government debt issues implied via (9) by these mean values together with a risk aversion coefficient of four. ${ }^{23}$

The use of point-in-time rather than time-averaged data apparently makes little difference for the implied effects of government deficit financing on the structure of relative expected returns. For the shortterm debt return again assumed to be fixed, the results shown in Table 5 indicate that the expected long-term debt return and the expected equity return fall by $.03 \%$ and $.31 \%$, respectively, and the expected differential between them narrows by $.28 \%$, in response to each $\$ 100$ billion additional supply of short-term government debt. Similarly, the expected long-term debt return rises by $.09 \%$ and the expected equity return falls by $.27 \%$, so that the expected differential between them narrows by $.37 \%$, in response to each $\$ 100$ additional supply of long-term government debt. 


\section{Results Based on an Alternative Estimation Strategy}

The analysis of investors' portfolio behavior in sections III and IV draws on the conditional variance-covariance structure inferred by applying the forecasting procedure described in section II, but it makes no use of the corresponding inferred sets of conditionally expected returns. Given these time series of expected returns, and given comparable data on investors' actual asset holdings, an alternative strategy for learning about the asset substitutability matrix $B$ is to estimate (5) by time series regression.

Individual investors, either on their own or through intermediaries, are the ultimate holders of the great majority of all private and government securities issued in the United States. Table 6 indicates the composition of the aggregate portfolio of financial assets held directly by U.S. households, as of yearend 1980, exhaustively arranged according to the three major asset classes under examination here. Comparable data are readily available for the end of each calendar quarter during 1960-1980.

Because there is substantial evidence that individual investors do not fully rebalance their portfolios within a time span as short as one quarterm year, it is appropriate not to estimate (5) directly but to imbed it within some model of portfolio adjustment out of equilibrium. The most familiar such model in the asset demand literature is the multivariate partial adjustment form

$$
\frac{\Delta A}{t}=\theta\left(\frac{A}{t}-\frac{A}{t-1}\right)
$$

where $\underline{A}^{*}$ is the vector of equilibrium asset holdings corresponding to $\underline{\alpha}^{*}$ in (5), and $\Theta$ is a matrix of adjustment coefficients with columns satisfying "adding up" constraints analogous to those applying to B. Substituting for 


\section{TABLE 6}

THREE-CLASS DISAGGREGATION OF HOUSEHOLD SECTOR FINANCIAL ASSETS

Asset Class

Short-Term Debt (s)

Money

Regulated-Return Time and Saving Deposits Competitive-Return Time Deposits Money Market Fund Shares

U.S. Government Securities Open Market Paper

Long-Term Debt (L)

U.S. Government Securities

State and Iocal Government Obligations Corporate and Foreign Bonds

Mortgages

Equity (E)

Mutual Fund Shares

Directly Held Equity Shares
1980:IV Value

$\$ 1,777.0$

268.0

624.7

669.7

74.4

102.0

38.2

464.3

180.2

74.2

86.9

122.5

$1,215.6$

63.7

$1,151.8$

Total

$\$ 3,456.9$

Notes: Values in billions of dollars. Detail may not add to total because of rounding.

Source: Board of Governors of the Federal Reserve system. 
$\underline{A^{*}}$ from (3) and (5) yields

$$
\frac{\Delta A}{t}=\theta B\left(\underline{r}_{t}^{e}+\underline{1}\right) \cdot W_{t}+\theta \underline{H} \cdot w_{t}-\theta_{t-1}
$$

Table 7 shows the results (B estimates and summary statistics only) of applying nonlinear maximum likelihood estimation to (17), for quarterly data spanning 1960-1980, using data on actual household sector asset holdings for $\underline{A}$ and the one-period-ahead after-tax real return forecasts described in Section II for $\underline{r}^{e} \cdot{ }^{24}$ Because each term in (17) has the dimension of nominal dollars, care is necessary to avoid spurious correlations due

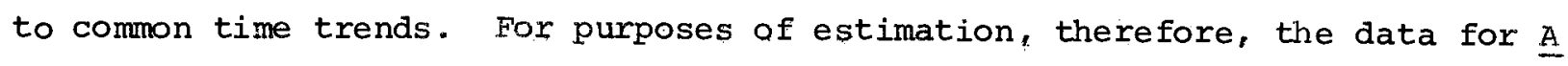
(and hence $w$ ) are rendered in real per capita values, using the consumer price index and the total U.S. population series. In addition, both $\Delta A$ and $w_{t}$ exclude the current period's capital gains or losses (although the vector of lagged asset stocks $\frac{A}{t-1}$ reflects previous periods' gains and losses), so that the estimated form focuses strictly on the household sector's aggregate net purchases or sales of each asset associated with the sector's net saving. Defining the asset flows in this way is equivalent to assuming that investors do not respond within the quarter to that quarter's changes in their holdings due to changing market valuations, but do respond to market valuations as of the beginning of each quarter. The upper panel of Table 7 reports summary statistics and estimated $\beta_{i j}$ values for each of the three asset demand equations, estimated in this way with no further constraints. These $\beta_{i j}$ estimates bear little apparent relation to the corresponding values shown in Table 3 - or, for that mattter, to any asset demand response matrix that makes sense in theoretical terms. The estimated response of the demand for equities to the expected return on equity is negative, and two of the three pairs of off-diagonal elements bear 
Unconstrained Estimates

\begin{tabular}{|c|c|c|c|c|c|c|}
\hline & $\beta \cdot S$ & $B_{\cdot L}$ & $B_{\cdot E}$ & $\bar{R}^{2}$ & $\mathrm{SE}$ & DW \\
\hline $\mathbf{S}$ & $\begin{array}{l}.00923 \\
(0.6)\end{array}$ & $\begin{array}{c}-.0000482 \\
(-0.0)\end{array}$ & $\begin{array}{l}.00190 \\
(1.1)\end{array}$ & .79 & 11.49 & 1.66 \\
\hline L & $\begin{array}{l}-.00515 \\
(-0.9)\end{array}$ & $\begin{array}{c}.0000231 \\
(0.0)\end{array}$ & $\begin{array}{l}-.000338 \\
(-0.5)\end{array}$ & .19 & 10.24 & 1.61 \\
\hline $\mathrm{E}$ & $\begin{array}{l}-.00408 \\
(-0.4)\end{array}$ & $\begin{array}{c}.0000251 \\
(0.0)\end{array}$ & $\begin{array}{l}-.00157 \\
(-1.4)\end{array}$ & .16 & 3.68 & 1.68 \\
\hline \multicolumn{7}{|c|}{ Constrained Estimates } \\
\hline & B.S & $B \cdot L$ & ${ }^{B} \cdot E$ & $\overline{\mathrm{R}}^{2}$ & SE & DW \\
\hline$S$ & $\begin{array}{l}-.00255 \\
(-2.5)\end{array}$ & & & .80 & 11.36 & 1.65 \\
\hline L & $\begin{array}{l}.000645 \\
(1.8)\end{array}$ & $\begin{array}{l}-.000294 \\
(-1.2)\end{array}$ & & .20 & 10.17 & 1.58 \\
\hline $\mathrm{E}$ & $\begin{array}{l}.00191 \\
(2.8)\end{array}$ & $\begin{array}{l}-.000351 \\
(-1.4)\end{array}$ & $\begin{array}{l}-.00156 \\
(-3.3)\end{array}$ & .17 & 3.66 & 1.69 \\
\hline
\end{tabular}


opposite signs. Moreover, the "fit" is poor for the demands for longterm debt and equity. 25

The lower panel of Table 7 reports analogous results for the estimation of (17) subject to the further constraint that matrix $B$ be symmetric. Imposition of the symmetry restriction is not inconsistent with the data, but the constrained estimates are even less plausible than their unconstrained counterparts. 26 The estimated responses of all three asset demands to their respective "own" expected returns are negative, and two of the three asset pairs are not substitutes but complements. Although asset complementarity is plausible enough in general, in this context there is nothing in either the conditional variance-covariance structures summarized in Table 2 or the unconditional variance-covariance structure shown in Table 1 to suggest complementarity among any of these asset pairs. Finally, and not surprisingly, the effects of government deficit financing implied by the two sets of $\beta_{i j}$ estimates reported in Table 7 . are also uninteresting. The two sets of implied effects on expected asset returns contain two sign contradictions, and each set includes at least one implied effect in excess of $100 \%$ lagain, for a $\$ 10.0$ billion change in the supply of debt). 
*I am grateful to Jeffrey Fuhrer for research assistance and many helpful discussions; to Gary Smith for several specific suggestions that I have implemented here; to Andrew Abel and Lawrence Summers for helpful comments on an earlier draft; to Jeffrey Frankel for pointing out an error in some earlier calculations; and to the National Science Foundation, the National Bureau of Economic Research and the Alfred P. Sloan Foundation for research support.

1. For a formal statement of the argument summarized here, see Friedman (1978). The focus of this paper is strictly on effects associated with financing the deficit, rather than with effects of taxes and government spending on real economic activity or price inflation. 2. It necessarily does so if all assets are gross substitutes in investors '
portfolios, and for plausible values of the relevant covariance parameters it may do so even if some assets are complements. The argument here implicitly assumes that investors perceive government debt to have net asset value - in other words, to be "net wealth" at least in part.

3. The principal advantage to using utility functions exhibiting constant relative risk aversion is that, as Cass and stiglitz (1970) among others have shown, they imply asset demands strictly proportional to wealth. In the context of the analysis here, the key implication of this assumption is the implied unit wealth elasticity of asset demands. Friend and Blume (1975), for example, provided evidence from cross-section data supporting the assumption of constant relative risk aversion. King and Leape (1984), also using cross-section data, reported wealth elasticities for various assets that in most cases were not significantly different from unity.

4. Although Fama (1965) and others have shown that the distribution of individual securities returns is not strictly normal (or lognormal), Lintner (1975) has shown that the approximation involved here is close enough for most purposes; indeed, Fama and Macbeth (1973) have also relied on the normality assumption. Because the normal distribution in principle admits the possibility of negative gross returns, it is not strictly compatible with the assumption of constant relative risk aversion, but this approximation is hardly troubling either.

5. Alternatively, if one asset in $A$ is riskless, it is necessary to partition the asset demand system so thăt the expression equivalent to (5) gives the demands for the risky assets only. In that case $\Omega^{-1}$ replaces the second (matrix) term in (6), and $\mathbb{I}$ in (7) is a vector of zeroes. See Friedman and Roley (1979) for the details of these two derivations.

6. The rationale for mean-variance analysis provided by samuelson (1970) and Tsiang (1972), for example, suggests that mean-variance analysis per se is only an approximation that depends on (among other factors) a small time unit. The time unit used in the empirical work presented in this paper is a calendar quarter. Although the observed variation of some asset prices is large over this time unit, it is the expected variation that matters here. 
7. Lintner (1969) showed that, under the assumptions maintained here, the risk aversion characterizing the aggregate of investors is the harmonic mean of the respective risk aversion characterizing each investor, weighted by each investor's respective wealth endowment. (Lintner also showed that asset demands like those in (5) readily admit to aggregation over investors with diverse return assessments, but the analysis here treats all investors as having homogeneous assessments.)

8. The net supply $A_{i}^{S}$ is zero for any "inside" asset.

9. The marginal tax rates applied to interest and dividends are values estimated by Estrella and Fuhrer (1983), on the basis of Internal Revenue Service data, to reflect the marginal tax bracket of the average recipient of these two respective kinds of income in each year. The marginal tax rate applied to capital gains is an analogous estimate, including allowances for deferral and loss offset. features, due to Feldstein et al. (1983). Preliminary experimentation with the respective price deflators for gross national product and personal consumption expenditures indicated that the results presented in this paper are not very sensitive to the choice of specific inflation measure.

10. The omission of a time subscript from $\Lambda$ in (15) abstracts from changes over time in the capital gains tax rate. The rate actually used here, from Feldstein et al. (1983), assumes a different value in each calendar year, as do the respective rates on interest and dividends, from Estrella and Fuhrer (1983).

11. The estimated vector autoregression also includes a vector of constants.

12. An alternative procedure would be to "roll" rather than extend the sample each period by dropping the earliest observation so as to maintain the same sample size as each new observation is added. Limited experimentation indicated that using a rolling sample period leads to results that differ modestly from those reported below. With a rolling sample, the mean variance-covariance matrix corresponding to that reported in Table 2 is $(1.00 ; 3.24,55.21 ; 5.17,48.51)$.

13. In comparing these "fit" correlations to the corresponding serial correlations, it is helpful to recall that investors did not know the 1960-1980 serial correlation properties of these variables until after this period had ended. The forecasting procedure applied here uses only information that investors had at the time they needed to make each quarter's forecast.

14. Matrix $B$ in (6) is necessarily symmetrical, so that three on- and three off-diagonal elements suffice to summarize the entire matrix at any point in time. The values shown in Figure 3 and Table 3 below are scaled to reflect the expression of returns in per cent per annum.

15. The conditions for gross substitutability derived by Blanchard and Plantes (1977) do not strictly apply here, because there is no riskless asset, but in fact they are satisfied. 
16. See Friedman (1984b) for an argument relating weak asset substitutabilities, implied by this and other evidence, to the observed stable total debt-toincome ratio in the United states during this period.

17. The asset demand responses reported in Friedman (forthcoming), based on the unconditional variance-covariance structure shown in Table 1 , are of course even smaller in absolute value. For the three offdiagonal elements, for example, the mean values corresponding to those shown in Table 3 are $\beta_{S L}=-.578, \beta_{S E}=-.0635$, and $\beta_{L E}=-.150$.

18. Because (6) is nonlinear, the mean $\beta_{i j}$ values shown here differ slightly from the corresponding values that would result from applying (6) to mean $\omega_{i j}$ values shown in Table 2 .

19. This value is about in the midale of the range of available empirical estimates. Friend and Blume (1975) suggested a value in excess of two, Grossman and Shiller (1981) suggested Four, and̄ Friend anả Hasbiroūuck (1982) suggested six. Bodie et al. (forthcoming) also assumed a value of four in a context similar to the application here.

20. See again footnote 2 .

21. The basic point is due to working (1960). The data used to calculate the returns used in the analysis reported in sections II and III are quarterly averages.

22. The average rate on time and saving deposits is available only on a quarter-average basis.

23. For comparability with Table 3 , the results reported in the lower panel of Table 5 again use mean 1960-80 asset values in applying (9).

24. The nonlinear maximum-likelihood procedure facilitates not only the direct estimation of t-statistics on the $\beta_{i j}$ coefficients but also the imposition of constraints as discussed below.

25. The standard errors have the dimension of thousands of constant 1967 dollars per capita. For purposes of comparison with the values shown in Table 6 , the $1980:$ IV values of the consumer price index and the total U.S. population are 2.658 and 228.6 million, respectively.

26. The test statistic for the symetry restriction is $\chi^{2}(3)=2.65$, not warranting a rejection at any plausible significance level. This result contrasts with the rejections of symmetry reported in Roley (1983) and Friedman (forthcoming). The further restriction that the estimated B matrix be strictly proportional (to allow for an unknown risk aversion coefficient) to the $B$ matrix shown in Table 3 is clearly inconsistent with the data, however; the test statistic for this additional restriction is $\chi^{2}(2)=10.14$, warranting a rejection at the .01 level. 
Re ferences

Blanchard, Olivier J., and Plantes, Mary Kay. "A Note on Gross Substitutability of Financial Assets." Econometrica, 45 (April, 1977), 769-771.

Bodie, Zvi, Kane, Alex, and McDonald, Robert. "The Role of Bonds in Investors' Portfolios." In Friedman (ed.), Corporate Capital Structures in the United States. Chicago: University of Chicago Press, forthcoming.

Cass, David, and Stiglitz, Joseph E. "The Structure of Investor Preferences and Asset Returns, and Separability in Portfolio Allocation: A Contribution to the pure Theory of Mutual Funds." Journal of Economic Theory, 2 (March, 1970) 122-160.

Estrella, Arturo, and Fuhrer, Jeffrey. "Average Effective Marginal Tax Rates on Interest and Dividend Income in the United States, 1960-1979." Mimeo: National Bureau of Economic Research, 1983.

Fama, Eugene F. "The Behavior of Stock Prices." Journal of Business, 38 (January, 1965), 34-105.

Fama, Eugene F. and Macbeth, James D. "Risk, Return, and Equilibrium: Empirical Tests." Journal of Political Economy, 81 (May/June,1973), 607-636.

Feldstein, Martin, Poterba, James, and Dicks-Mireaux, Louis. "The Effective Tax Rate and the Pretax Rate of Return." Journal of Public Economics, 21 (July, 1983), 129-158.

Friedman, Benjamin M. "Crowding Out or Crowding In? Economic Consequences of Financing Government Deficits." Brookings Papers on Economic Activity (No. 2, 1978), 593-641.

Friedman, Benjamin M. "Implications of Debt-Equity Substitutability for Interest Rates and Corporate Financing." Mimeo: National Bureau of Economic Research, 1984a,

Friedman, Benjamin M. "Portfolio Choice and the Debt-to-Income Relationship." Mimeo: National Bureau of Economic Research, 1984b.

Friedman, Benjamin M. "The Substitutability of Debt and Equity Securities." In Friedman (ed.), Corporate Capital structures in the United States. Chicago: University of Chicago Press, forthcoming.

Friedman, Benjamin M., and Roley, V. Vance. "A Note on the Derivation of Linear Homogeneous Asset Demand Functions." Mimeo: National

Bureau of Economic Research, 1979.

Friend, Irwin, and Blume, Marshall E. "The Demand for Risky Assets." American Economic Review, 65 (December, 1975) 900-922.

Friend, Irwin, and Hasbrouck, Joel. "Effect of Inflation on the Profitability and Valuation of U.S. Corporations." In Sarnat and Szego (eds.), Savings, Investment and Capital Markets in an Inflationary Economy. Cambridge: Ballinger, 1982 . 
Grossman, Sanford J., and Shiller, Robert J. "The Determinants of the Variability of Stock Prices." American Economic Review, 71 (May $1981), 222-227$.

Ibbotson, Roger G., and Sinquefield, Rex A., Stocks, Bonds, Bills and Inflation: The Past and the Future. Charlottesville: Financial Analysts Research Foundation, 1982.

King, Mervyn A., and Leape, Jonathan I. "Wealth and Portfolio Composition: Theory and Evidence." Mimeo: National Bureau of Economic Research, 1984 .

Lintner, John. "The Aggregation of Investors' Diverse Judgments and Preferences in Purely Competitive Security Markets." Journal of Financial and Quantitative Analysis, 4 (December, 1969), 347-400.

Iintner, John. "The Lognormality of Security Returns, Portfolio Selection and Market Equilibrium." Mimeo: Harvard University, 1975.

Roley, v. Vance. "Symmetry Restrictions in a System of Financial Asset Demands: Theoretical and Empirical Results." Review of Economics and Statistics, 65 (February, 1983), 124-130.

Samuelson, Paul A. "The Fundamental Approximation Theorem of Portfolio Analysis in Terms of Means, Variances, and Higher Moments." Review of Economic Studies, 37 (October, 1970), 537-542.

Tsiang, S.C. "The Rationale for the Mean-Standard Deviation Analysis, Skewness Preference, and the Demand for Money. American Economic Review, 65 (June, 1972), 354-371.

Working, Holbrook. "Note on the Correlation of First Differences in a Random Chain." Econometrica, 28 (October, 1960), 916-918. 